\title{
Transient Thermal Analyses of Passive Systems on SCEPTOR X-57
}

\author{
Jeffrey C. Chin, ${ }^{*}$ Sydney L. Schnulo, ${ }^{\dagger}$ Andrew D. Smith, ${ }^{\ddagger}$ \\ NASA Glenn Research Center, Cleveland, OH, 44135, U.S.A.
}

\begin{abstract}
As efficiency, emissions, and noise become increasingly prominent considerations in aircraft design, turning to an electric propulsion system is a desirable solution. Achieving the intended benefits of distributed electric propulsion (DEP) requires thermally demanding high power systems, presenting a different set of challenges compared to traditional aircraft propulsion. The embedded nature of these heat sources often preclude the use of traditional thermal management systems in order to maximize performance, with less opportunity to exhaust waste heat to the surrounding environment.

This paper summarizes the thermal analyses of X-57 vehicle subsystems that don't employ externally air-cooled heat sinks. The high-power battery, wires, high-lift motors, and aircraft outer surface are subjected to heat loads with stringent thermal constraints. The temperature of these components are tracked transiently, since they never reach a steadystate equilibrium. Through analysis and testing, this report demonstrates that properly characterizing the material properties is key to accurately modeling peak temperature of these systems, with less concern for spatial thermal gradients. Experimentally validated results show the thermal profile of these systems can be sufficiently estimated using reduced order approximations.
\end{abstract}

\section{Nomenclature}

$m$

$M_{\text {chord }}$

$\mathrm{Nu}$

$P$ cross sectional Area $\left(\mathrm{m}^{2}\right)$

thermal diffusivity $\left(\frac{m^{2}}{s}\right)$

specific heat $\left(\frac{J}{K}\right)$

diameter $(m)$

emissivity

Solar Irradiance $\left(\frac{W}{m^{2}}\right)$

gravity $\left(\frac{m^{2}}{s}\right)$

Heat Capacity $\left(\frac{J}{K}\right)$

convection heat transfer coefficient $\left(\frac{W}{m^{2} K}\right)$

thermal discharge efficiency

current $(A)$

thermal conductivity of air $\left(\frac{W}{m * K}\right)$

Length $(m)$

mass $(k g)$

Standard mean chord $(m)$

Nusselt number

Power $(W)$
$P_{r} \quad$ Prandtl Number

$R_{e} \quad$ Reynolds Number

$\gamma_{a} \quad$ atmospheric ratio of specific heats

$\dot{Q} \quad$ heat transfer rate $\left(\frac{W}{s}\right)$

$q^{\prime} \quad$ heat transfer rate per unit length $\left(\frac{W}{m * s}\right)$

$R^{\prime} \quad$ electrical resistance per unit length $\left(\frac{K}{m * K}\right)$

$R a_{D} \quad$ Rayleigh Number

density $\left(\frac{\mathrm{kg}}{\mathrm{m}^{3}}\right)$

hemispherical reflectivity

$\begin{array}{ll}\rho_{r} & \text { hemispherical re } \\ S_{\text {wing }} & \text { Wing Area }\left(\mathrm{m}^{2}\right)\end{array}$

$\sigma \quad$ Stefan-Boltzmann Constant $\left(\frac{W * m}{K^{4}}\right)$

$t \quad$ time $(s)$

$T \quad$ temperature $(K)$

$\theta_{i} \quad$ Surface to ambient temperature delta $(K)$

$u_{o} \quad$ free stream velocity $\left(\frac{m}{s}\right)$

$\nu \quad$ kinematic viscosity of air $\left(\frac{m^{2}}{s}\right)$

*Propulsion System Analysis Branch, jeffrey.c.chin@nasa.gov, AIAA Member.

$\dagger$ Propulsion System Analysis Branch, sydney.l.schnulo@nasa.gov, AIAA Member.

¥Aerospace Engineer, Vantage Partners LLC, Brookpark OH, andrew.d.smith@nasa.gov AIAA Member. 


\section{Introduction}

The Scalable Convergent Electric Propulsion Technology Operations Research (SCEPTOR) project is an effort put forth by NASA to demonstrate the significantly higher efficiency of electric aircraft over conventional aircraft during cruise. The experimental aircraft, designated as X-57 Maxwell, has twelve small electric propulsors distributed along the wingspan, with two larger wingtip propulsors on either end. During initial climb and final descent, all of the propulsors are engaged to increase the airspeed over the wing, effectively augmenting lift. ${ }^{1}$ This enables a narrow high-aspect wing area, resulting in less drag during cruise operation. The unique high lift propellers (HLP) fold against their nacelle to further reduce drag during the cruise. The thermal design of the wingtip propulsors are the main focus of alternate works, ${ }^{2,3}$ and focus on the design of cooling systems for the cruise motor and inverter. These analyses do not integrate the temperature state across the entire mission, since there is sufficient cooling to approximate "worst-case" scenarios using steady-state energy balances. The cases are calculated during takeoff when the electrical components are producing the highest thermal load and the environment is providing the least cooling.

This paper focuses on the thermal considerations for the remainder of the airplane aside from the wingtip nacelles. These components pose a thermal challenge since they do not have the ability to reject heat through finned heat sinks that are exposed to incoming ambient air. Determining the peak temperatures for the battery, HLP nacelles, and wires necessitate transient calculations that are dependent on the mission power profile, since the steady-state temperatures would significantly exceed thermal limits. These systems rely on their heat capacity to remain within thermal limits, since the vehicle does not operate long enough in its maximum high-power condition to reach an equilibrium temperature. After the initial climb, the vehicle is exposed to cooler ambient air and power levels are reduced. Tracking the transient state of these systems is therefore necessary to assess temperature during any snapshot of the mission.

\section{A. Mission}

X-57's flight will take place in Edwards, California which can reach temperatures up to $120^{\circ} \mathrm{F}\left(49^{\circ} \mathrm{C}\right)$. The pilot will takeoff using both the HLP motors and cruise motors. Once an altitude of 1,000 feet is reached, the HLP motors will power off and the cruise motors will climb to the cruise altitude of 8,000 feet at 150 knots. This altitude will be maintained for 6 minutes before beginning descent. At final approach, the HLP motors are again activated. The details of the power being transmitted to each part of the system is shown in Table 1.

\begin{tabular}{|l|c|c|c|}
\hline \multicolumn{1}{|c|}{ Phase } & Duration (s) & Total Cruise Power & Total HLP Power \\
\hline Taxi & 600 & 10 & 0 \\
TO Checklist & 120 & 0 & 0 \\
Cruise Run-up & 30 & 120 & 0 \\
HLP Run-up & 30 & 0 & 120 \\
Flight go/no-go & 30 & 0 & 0 \\
Ground roll & 10 & 120 & 120 \\
Climb to 1500' & 90 & 120 & 90 \\
Cruise Climb & 540 & 120 & 0 \\
Cruise & 300 & 90 & 0 \\
Descent to 1500' & 450 & 60 & 0 \\
Final Approach & 180 & 0 & 90 \\
Go Around to 1500' & 90 & 120 & 90 \\
Approach Pattern & 90 & 120 & 0 \\
Final Approach & 180 & 15 & 90 \\
Rollout, Taxi & 660 & 10 & 0 \\
\hline
\end{tabular}

Table 1. X57 Mission Profile 


\section{B. Vehicle Description}

Batteries are contained in eight boxes located behind the pilot, as shown on the right in Figure 1. Two dedicated power buses provide electricity to the wingtip motor, while the other two are shared by all of the HLP systems. An internal view of the wing is shown in Figure 2 showing the wire runs along four rigid ducts within the each wing. The vehicle will be flight tested in four discrete stages, as covered in previous work, ${ }^{1}$ the left image in Figure 1 shows the difference in wing shape between the original wing used in Mods I\&II, versus the final wing design in Mod III\&IV.

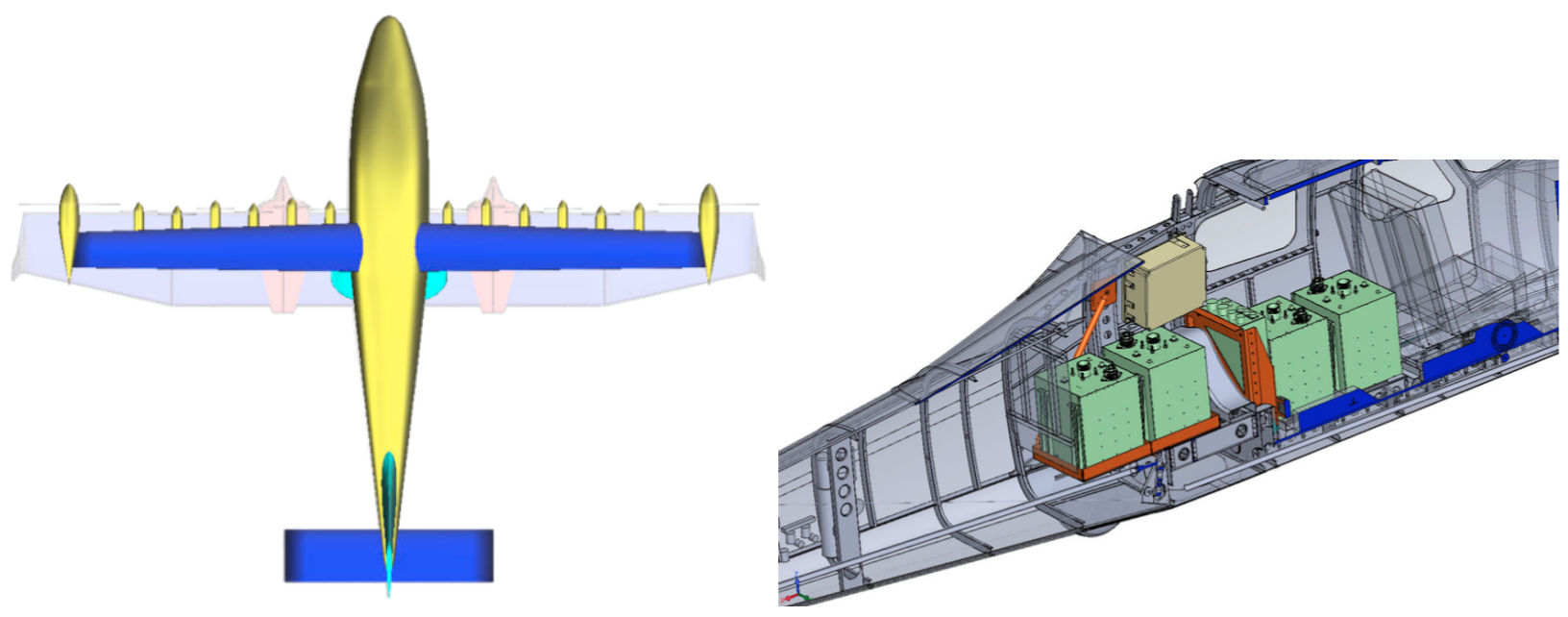

Figure 1. (Left) Faded stock Tecnam Mod I\&II top view vs Mod III\&IV wing configuration. (Right) Battery pack location behind pilot's seat, image shows half the vehicle, which would be mirrored

Despite each of these systems sharing the same power profile, each reaches a peak temperature during different stages of the mission. There is no thermal coupling between these systems, and the estimated thermal profile is discussed independently in the subsequent sections.

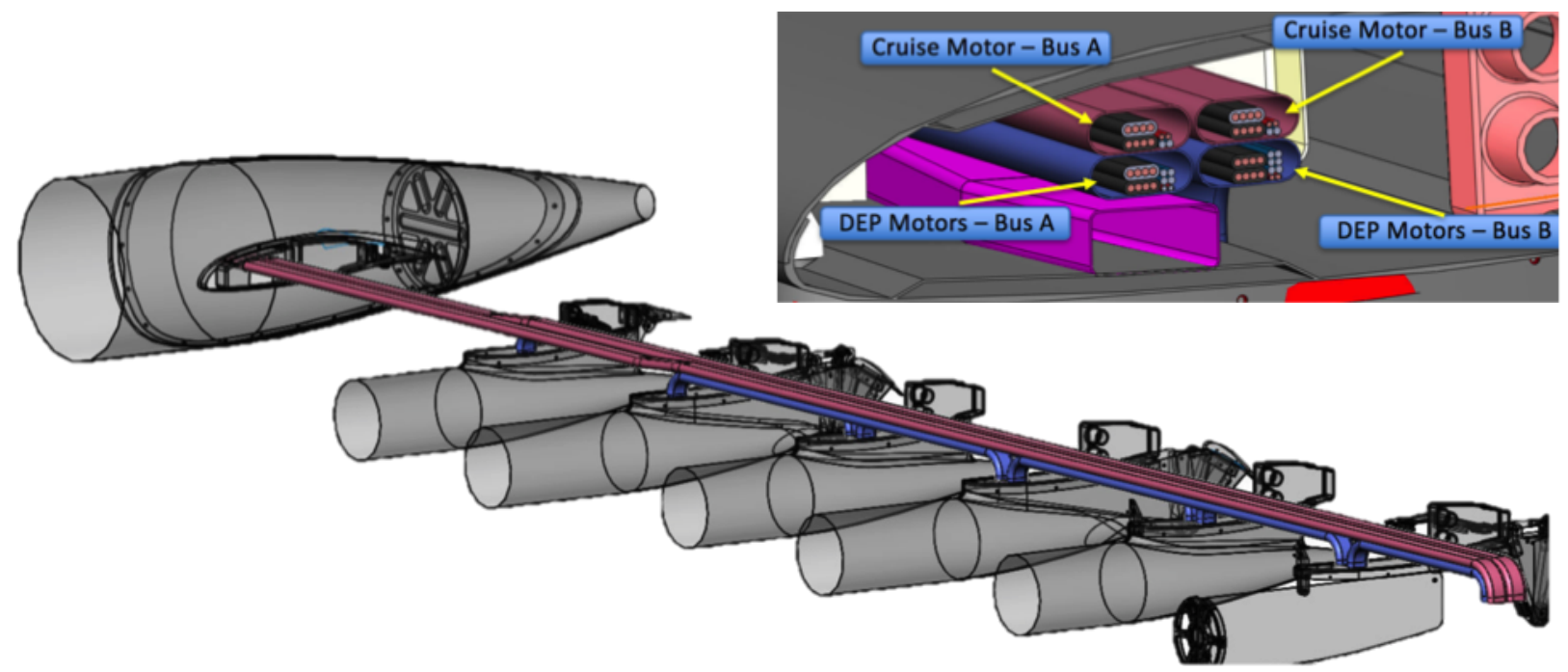

Figure 2. Cruise traction bus shown in maroon, DEP bus Shown in blue. Wing structure hidden for visual clarity, within an expanded cross section on the top right.

\section{Power Bus Transient Thermal Analysis and Testing}

The wires that carry power from the batteries to the motors pose a thermal challenge due to numerous design constraints. The ducts interact with critical structural members along the high aspect ratio wing, whose composite resins impose a very low thermal limit. The wires must also provide sufficient electromagnetic interference (EMI) shielding, and be flexible enough to route through the numerous motor nacelles 
along the wing span. Multiple wire types were considered, ultimately choosing Parallel PowerCable ${ }^{\mathrm{TM}}$ (PPC) for its compact profile, flexibility, commercial availability, and termination lugs.

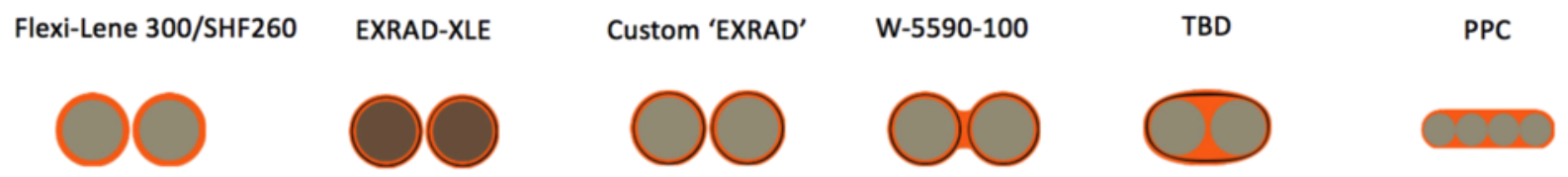

Figure 3. Cable selection options, all assuming an equivalent 4AWG and sized based on SAE AS50991. The PPC wire on the right was chosen for the final design.

Each cable consists of four 10 gauge wires in both the supply and return, which are stacked on each other to minimize inductance. This configuration is utilized for both the cruise and distributed electric propulsion (DEP) motors, which are then secured in the rigid duct that runs the length of the wing. A cross section of the duct is shown in Figure 2. The duct structure has a temperature that cannot exceed $165^{\circ} \mathrm{F}$, or about $78^{\circ} \mathrm{C}$. However, the preferred operating temperature is $68^{\circ} \mathrm{C}$. This duct then connects to structural ribs in the wing that have the same temperature limits.

In order to predict the thermal behavior of the wires throughout the mission, a thermal model was developed in python. The quasi-1D model quantifies the peak temperature at the center of the wire bundle, conservatively assuming the ambient conditions remain at sea-level hot day condition throughout the flight. The wire generates heat from joule heating uniformly along the length of the wire, with no substantial method of cooling. Therefore, a transient thermal analysis of the system must be completed to ensure that these temperature constraints are met. The heat flux per unit length $\left(\frac{W}{m}\right)$ is defined as the current $(A)$ traveling through the wires squared multiplied by the resistance per unit length $\frac{\Omega}{m}$ cited by the manufacturer.

$$
q_{w i r e}^{\prime}=I^{2} * R^{\prime}
$$

The combined heat capacity of the wires and insulating jacket is a function of the material density $\rho$, specific heat $C_{P}$, and area as depicted in equation 2. The heat transfer rate, $\dot{Q}$, across the system is normalized per length as expressed in equation 3. Finally, the temperature rate of change (ROC) $\frac{\delta T}{\delta t}$, is calculated using the heat balance per unit length divided by the combined heat capacity, $H C\left(\frac{J}{K * m}\right)$, in equation $4^{4}$

$$
\begin{gathered}
H C=\rho * C_{P} * A \\
q^{\prime}=\frac{\dot{Q}}{L} \\
R O C_{T}=\frac{\delta T}{\delta t}=\frac{q_{\text {wire }}^{\prime}-q_{o u t}^{\prime}}{H C}
\end{gathered}
$$

An adaptive time-stepping integration is then performed to solve the ordinary differential equation (ODE) to track the temperature state of the wires throughout the mission profile. The ODE solver used ${ }^{5}$ automatically switches between non-stiff and stiff solvers depending on the on the behavior of the transient.

$$
T_{n+1}=T_{n}+\Delta t \frac{\delta T}{\delta t}
$$

The cable manufacturer does not provide the exact density and specific heat of the copper wire and insulating jacket combination, so testing was performed in order to ensure that the heat capacity estimate being used in the model is reasonable. This testing also validated the zero dimensional modeling methods in which the net heat flux, accounting for joule heating and minor heat leakage, captures the thermal transient wire heating. 
The thermal characterization test was conducted in the NASA Electric Aircraft Testbed (NEAT) facility. The test setup operates two electric motors: one acting as the motor and the other as a generator to provide a torque load. The SCEPTOR power bus was installed to carry power to the motor; Figure 4 shows the test setup. The thermal experiment focused on a 3 foot section of the bus that was exposed to ambient air, and another 3 foot section that was tightly wrapped in fiberglass insulation to simulate an adiabatic case.

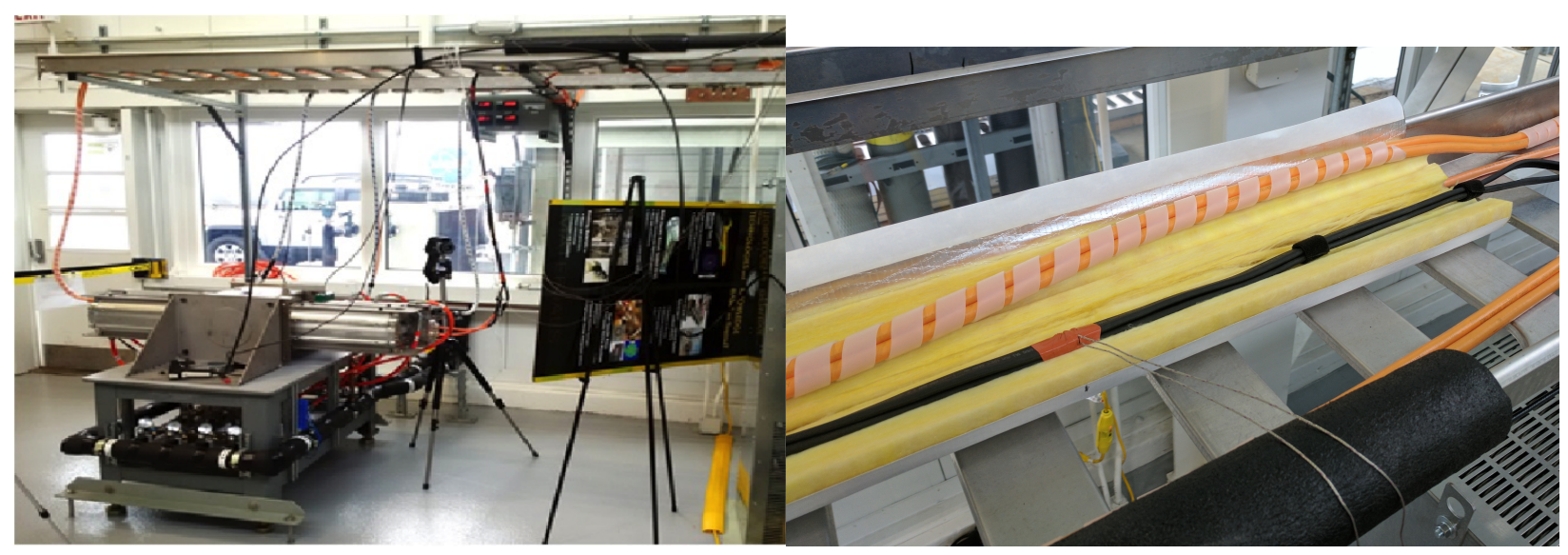

Figure 4. (Left) Wire thermal testing setup at NASA Plumbrook NEAT Facility (Right) Insulated Section

The two sections were outfitted with 4 thermocouples placed perpendicular to the power buses to ensure EMI shielding. The thermocouple data was corroborated by readings from an infrared camera on the open air section through the tests.

\section{Wire Test Data vs Model}

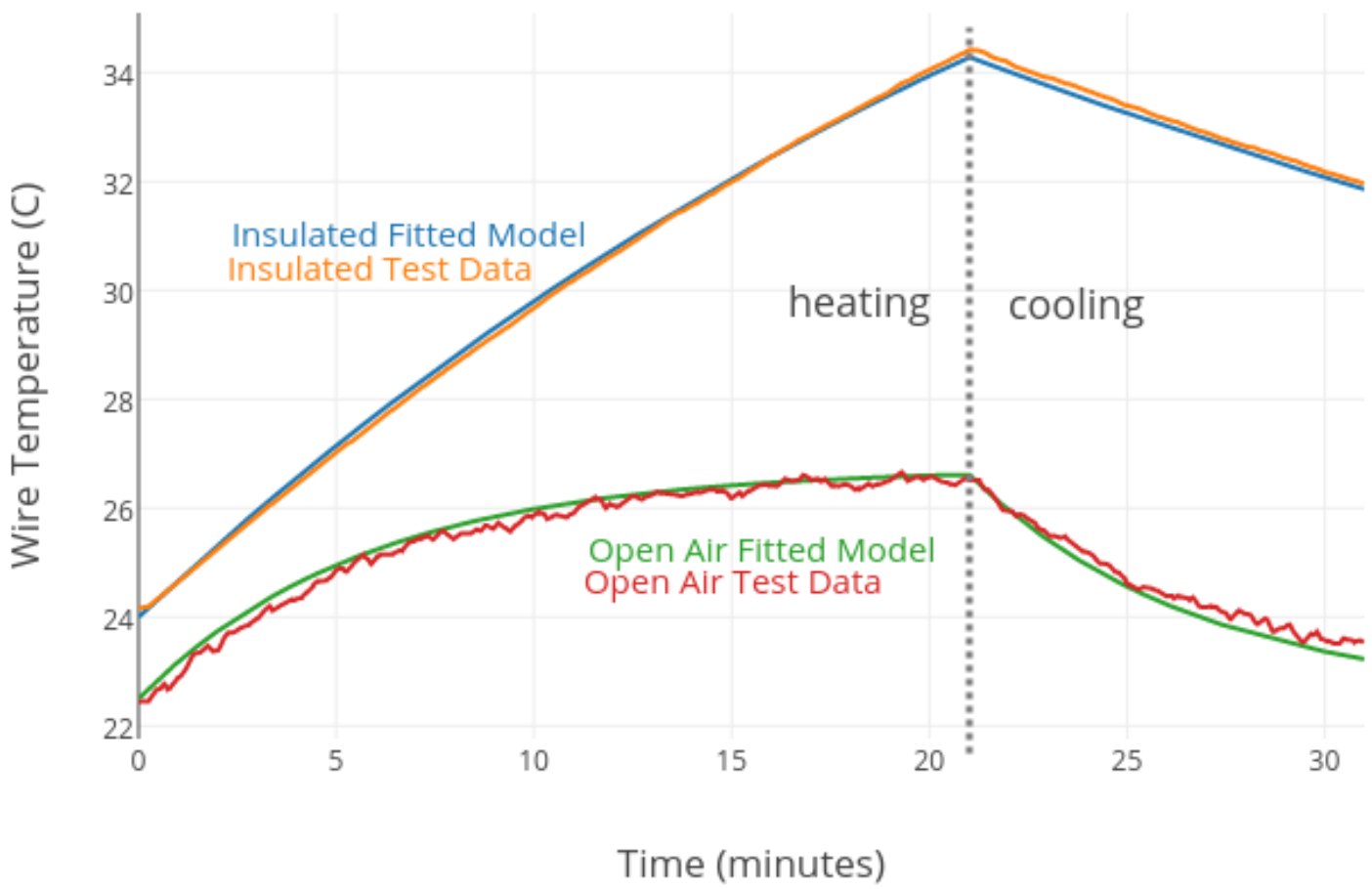

Figure 5. Test 1 thermocouple readings plotted against analytical models, for both insulated and open-air wire segments. 
The first test applied 416V, 55.3A continuously for 20 minutes until the steady-state wire temperature was achieved on the open-air wire. Temperature was then continuously monitored until the wire cooled back to ambient. Using the linearly fitted data from the insulated test section, the heat capacity per length of the wire could be deduced from the average temperature rise during heating. The heat capacity per length was found to be $240 \frac{J}{K * m}$, with $R^{2}$ value of 0.9968 . The convective heat transfer coefficient of the open-air section was then computed based on the equilibrium temperature achieved. Although the test did not accurately match the exact flight thermal conditions, a power profile matching Table 1 was performed to check the accuracy of the wire thermal model with matching conditions.

Using the thermocouple data, the open-air heat transfer coefficient in the NEAT facility was determined to be roughly $11 \frac{W}{m^{2} K}$. The error in the adiabatic case was caused by the imperfect insulation and slight environmental temperature changes due to the HVAC system in the facility. The model was then run using flight conditions starting at Armstrong hot day ambient temperature and varying with changing altitude. The separate HLP buses were also modeled to yield the predicted SCEPTOR power bus temperature profiles shown in Figure 6.

\section{Transient Wire Temperature}

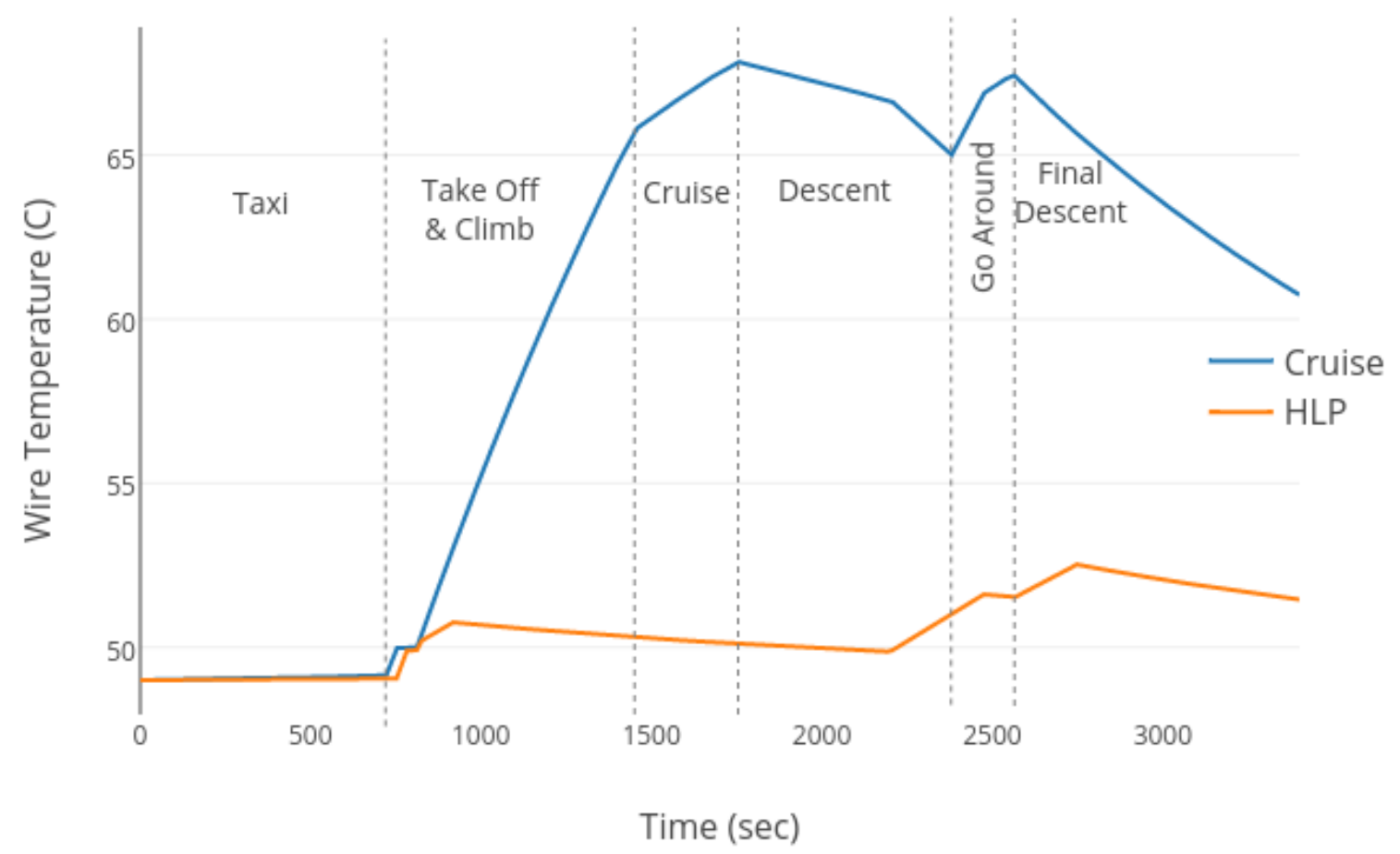

Figure 6. Simulated temperature profile of the cruise and high lift propulsor ducts based on the mission

As seen in Figure 6, which uses a very conservative heat transfer coefficient of $3.3 \frac{\mathrm{W}}{\mathrm{m}^{2} \mathrm{~K}}$, neither power bus is expected to exceed $68^{\circ} \mathrm{C}$. While it had originally been thought that using ambient air may be necessary to cool the buses, testing showed both that the non-dimensional modeling is sufficient to capture the transient effects of joule heating on the wire and the heat capacity of the power bus is sufficient to remain within vehicle system limits. If the power profile changes in future design iterations, the model can be adjusted to reflect the new behavior. The peak temperature of the cable runs may drop even lower in reality as the higher heat load from the cruise ducts get conducted into the adjacent cooler HLP ducts. 


\section{Equilibrium Wing Temperature Analysis}

A basic equilibrium heat balance is performed to determine the approximate wing skin temperature. The analysis ignores heat transfer time-lags, only considering heat addition from solar energy absorption, and heat released from radiative and natural convection cooling. The wing skin will likely reach its maximum temperature while sitting stationary on the ground, where the ambient temperature is the highest, and the wing does not benefit from forced convection. As a worst case analysis, the plane is assumed to sit idly for long enough to reach steady-state temperature. For this analysis, the entire upper surface of the wing is assumed to be unshaded and exposed to direct sunlight. Only direct solar irradiance $(\mathrm{G})$ is considered. At noon on a clear day, G may be up to $1,145 \frac{\mathrm{W}}{\mathrm{m}^{2}}$ as shown in Figure 7 . The heating rate due to solar irradiation is estimated by,

$$
Q_{\text {solar }}=\underbrace{\left(1-\rho_{r}\right) C_{\text {solar }} G}_{\text {Radiated Heat Flux Surface Area }} \underbrace{S_{\text {inf }}}_{\text {wing }}
$$

where $\rho_{r}$ is the total, hemispherical reflectivity of the wings exterior surface, $\mathrm{G}$ is the solar irradiance ${ }^{6}$ and $S_{\text {wing }}$ is the wing area. Joule heating coming from the powered motors negligibly contributes to heating before mission start, and is explored in the previous section. Once wire heating becomes relevant, the airplane will be at a high enough altitude that outer wing skin temperature is no longer a concern. At that point, only internal ducting structure temperatures are noteworthy. Radiative and convective heat transfer are identified as the primary heat loss mechanisms for the wing. Radiative heat transfer is a simple relation dependent on temperature difference between the wing and ambient atmosphere.

$$
Q_{\text {rad }}=\underbrace{\epsilon \sigma\left(T_{\text {wing }}^{4}-T_{\text {sky }}^{4}\right)}_{\text {Radiated Heat Flux Surface Area }} \underbrace{S_{\text {ind }}}_{\text {wing }}
$$

where $\epsilon$ is the total, hemispherical emissivity of the wing exterior surface, $\sigma$ is the Stefan-Boltzmann constant, and $T_{s k y}$ is the effective sky temperature. For a conservative estimation, a $T_{s k y}$ of $10^{\circ} \mathrm{C}$ was used. ${ }^{7}$ To determine the rate of natural convection off the surface of the wing, a flat plat correlation is assumed to model the wing. Simplified equations for laminar free convection from a heated plate facing upward is shown in equation 8 according to Holman 4 th edition Table 7-2. Here, $M_{\text {chord }}$ is defined as the standard mean chord of the wing.

\section{Solar Radiation}

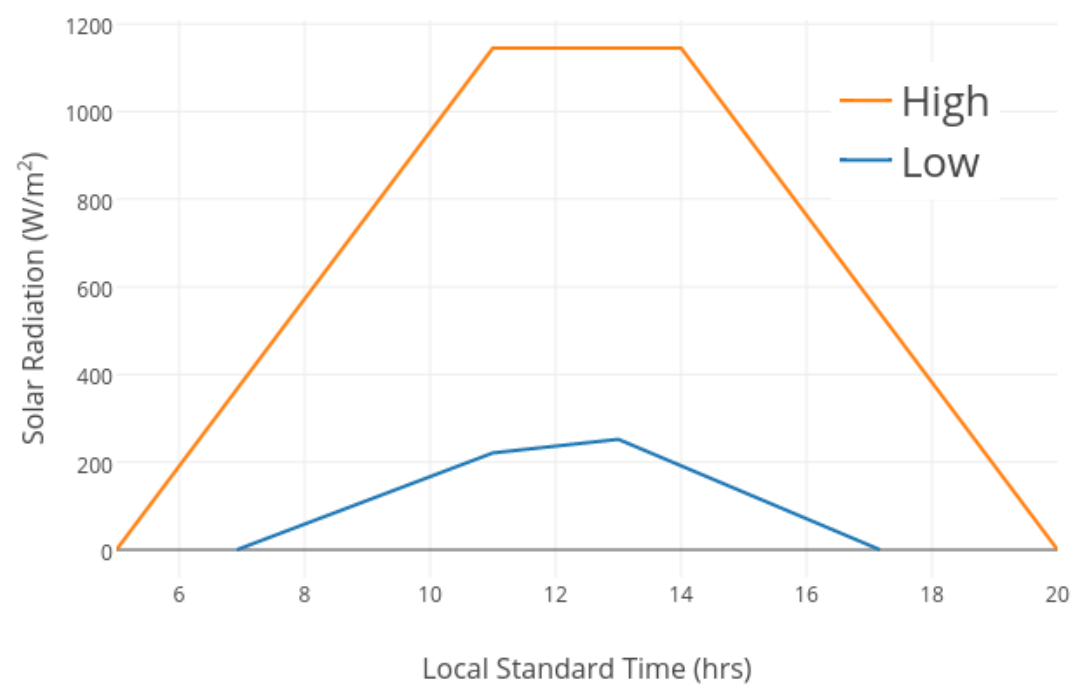

Figure 7. Recommended design high and low solar radiation at ground level ${ }^{7}$ 


$$
Q_{\text {conv }}=\underbrace{1.32 *\left(\frac{T_{\text {wing }}-T_{\text {amb }}}{M_{\text {chord }}}\right)^{0.25}}_{\text {Radiated Heat Flux }} \underbrace{S_{\text {wing }}}_{\text {Surface Area }} *\left(T_{\text {wing }}-T_{\text {amb }}\right)
$$

The equilibrium temperature can then be determined by varying $T_{\text {wing }}$ until the equality $Q_{\text {solar }}=$ $Q_{\text {rad }}+Q_{c o n v}$ is satisfied. A wind speed correction can then be applied to the final temperature differential, ${ }^{7}$ as depicted in Table 2.

\begin{tabular}{|l|c|c|c|c|}
\hline Windspeed $(\mathrm{m} / \mathrm{s})$ & 0 & 2 & 4 & 10 \\
\hline Correction Factor & 1. & 0.25 & 0.17 & 0.11 \\
\hline
\end{tabular}

Table 2. Based on NASA TM2008-215633 Table 4-12

Based on this model a steady state wing temperature of $71.5^{\circ} \mathrm{C}$ was computed. This value is highly dependent on the ambient wind speed, and is likely conservative. With even a small breeze, this temperature drops significantly. This analysis also assumes peak solar radiation and that the wing is painted glossy white paint $\left(\mathrm{BaSO}_{4}\right.$ and $\left.\mathrm{MgO}\right)$ with absorptivity $0.425^{7}$ and emissivity of 0.9 . The steady state temperature as a function of wind speed for two emissivity levels is shown in Figure 8. If the aircraft is subjected to a $45^{\circ} \mathrm{C}$ day with no wind at noon, it's advised to keep it shaded until flight.

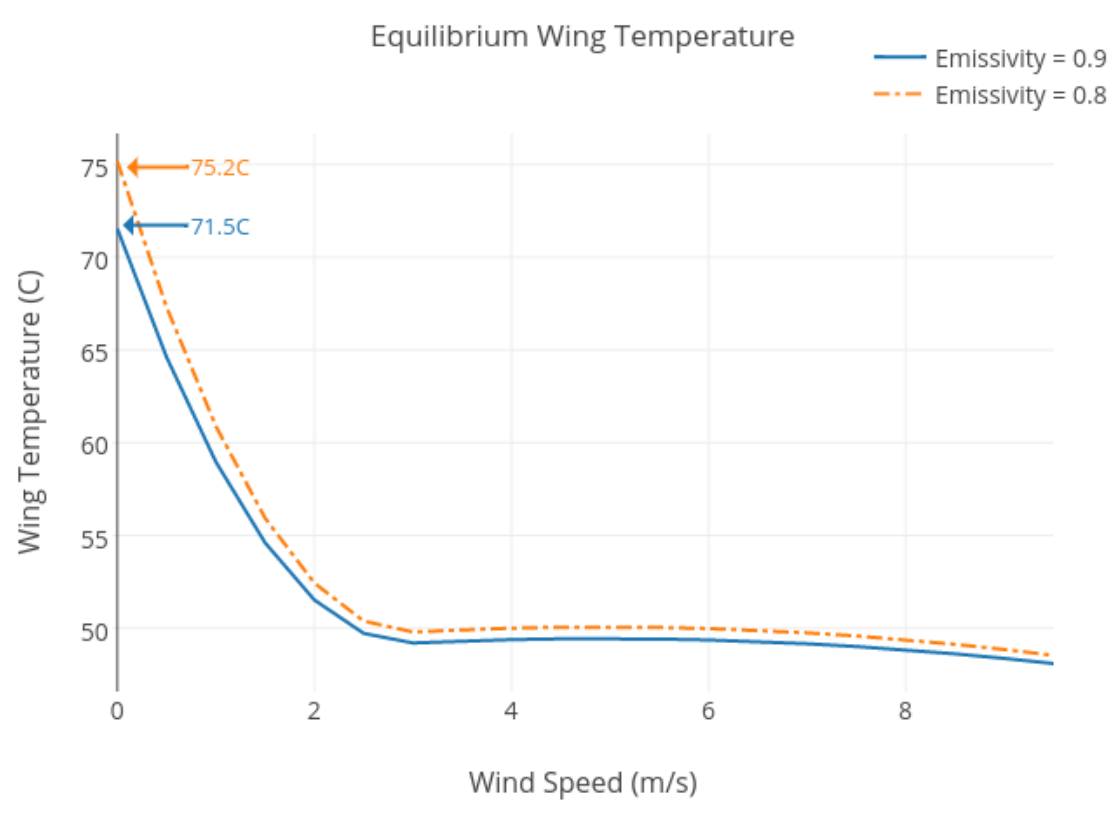

Figure 8. Equilibrium wing skin temperature as a function of ambient wind speed

\section{Battery Thermal Analysis}

The X-57 mod-II battery consists of a bank of 8 modules, each containing 640 Samsung 18650 Lithium Ion cells. Aside from a pressure relief vent, each enclosure is a sealed unit with no currently implemented thermal management system. Only the surface area of the cube-shaped enclosure is available for dissipation of heat generated in flight. With no conduction path from the cells to the enclosure wall, convection cooling to the aircraft cabin is likely inadequate for maintaining the modules at a stable temperature in flight.

To evaluate X-57 battery thermal performance, a zero-dimensional transient heating model was devised for a single 18650 cell, fully characterized by its discharge efficiency, mass and specific heat. From an initial condition (T0), the simulated 18650 cell was subjected to a heat load proportional to the time-indexed total cruise power from a sample X-57 Mod II mission profile. The cell temperature at each time step was 


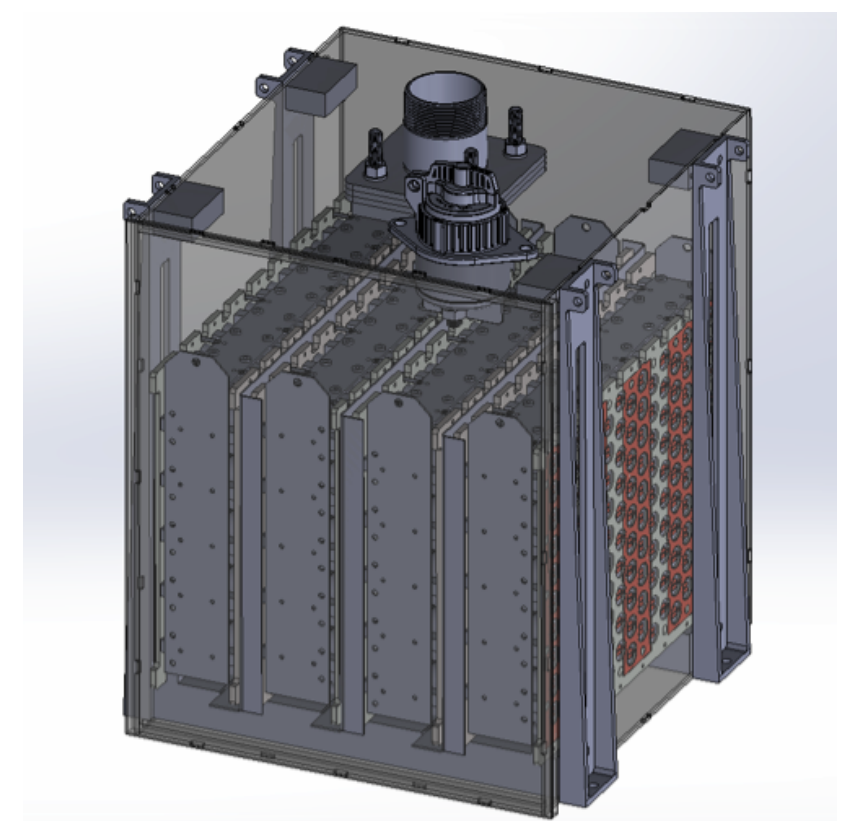

Figure 9. A single Mod II battery enclosure, containing 640 cells.

computed with a simple accounting of the dissipated heat within the cell,

$$
T_{n}=T_{n-1}+\frac{P_{\text {cruise }} / \eta}{N_{\text {config }} c_{p} m}
$$

where $P_{\text {cruise }}$ is the mission dependent cruise power, $\eta$ is the discharge efficiency, and $c_{p}$ and $\mathrm{m}$ are the cell specific heat and mass, respectively. $N_{\text {config }}$ is a battery module configuration scaling parameter, which determines the fraction of cruise power supplied by a single cell. A good battery thermal model requires good characterization of the lithium ion cell's thermal mass, and dissipated power. A search of the cell specification sheet, and survey of literature yields typical values for an 18650-type cell, which are largely standardized across the industry with the relevant parameters listed in Table 3.

\begin{tabular}{|l|c|c|}
\hline \multicolumn{1}{|c|}{ property } & value & units \\
\hline discharge efficiency & 0.95 & - \\
specific heat & 1.005 & $\mathrm{~J} /$ gram- $^{\circ} \mathrm{C}$ \\
mass & 45 & grams \\
discharge temp limits & -20 to 75 & ${ }^{\circ} \mathrm{C}$ \\
\hline
\end{tabular}

Table 3. 18650 Battery Properties

The thermal discharge efficiency is assumed to be constant for this analysis, when in reality, the amount of power lost to heat is closely dependent on battery discharge rate and state of charge. Improving this model is the subject of additional work. ${ }^{8}$ With a well-characterized cell, a sample X-57 Mod II mission profile was applied in Figure 10. From an initial temperature of $35^{\circ} \mathrm{C}$ (a "hot day" ground condition for Armstrong Flight Research Center), the isolated cell experiences a total adiabatic temperature rise of $30^{\circ} \mathrm{C}$. The most stressful phases are the full-power ground roll (takeoff) and climb segments. Battery thermal runaway is a risk above $60^{\circ} \mathrm{C}$, and propagation between cells can result in a cascading failure of an entire battery module. At least for the "hot day" conditions, it is useful to define a required minimum cooler to stabilize the battery temperature. As a thermal sizing model, it is flexible enough to accept a generic cooling load of the form,

$$
T_{n+1}=T_{n}+\frac{\frac{P_{\text {cruise }}}{\eta}-\left(T_{n}-T_{0}\right) h}{N_{\text {config }} c_{p} m}
$$

where the expression $\left(T_{n}-T_{0}\right) * h$ describes a generic cooler, with a rate proportional to the temperature 
difference between the cell and the environment. An overall heat transfer coefficient, $h$, can be chosen such that the simulated cell temperature never exceeds a predetermined safe operating limit. For the Mod II flight profile, $h=25 \frac{W}{m^{2} K}$ is sufficient:

\section{Battery with and without cooling}

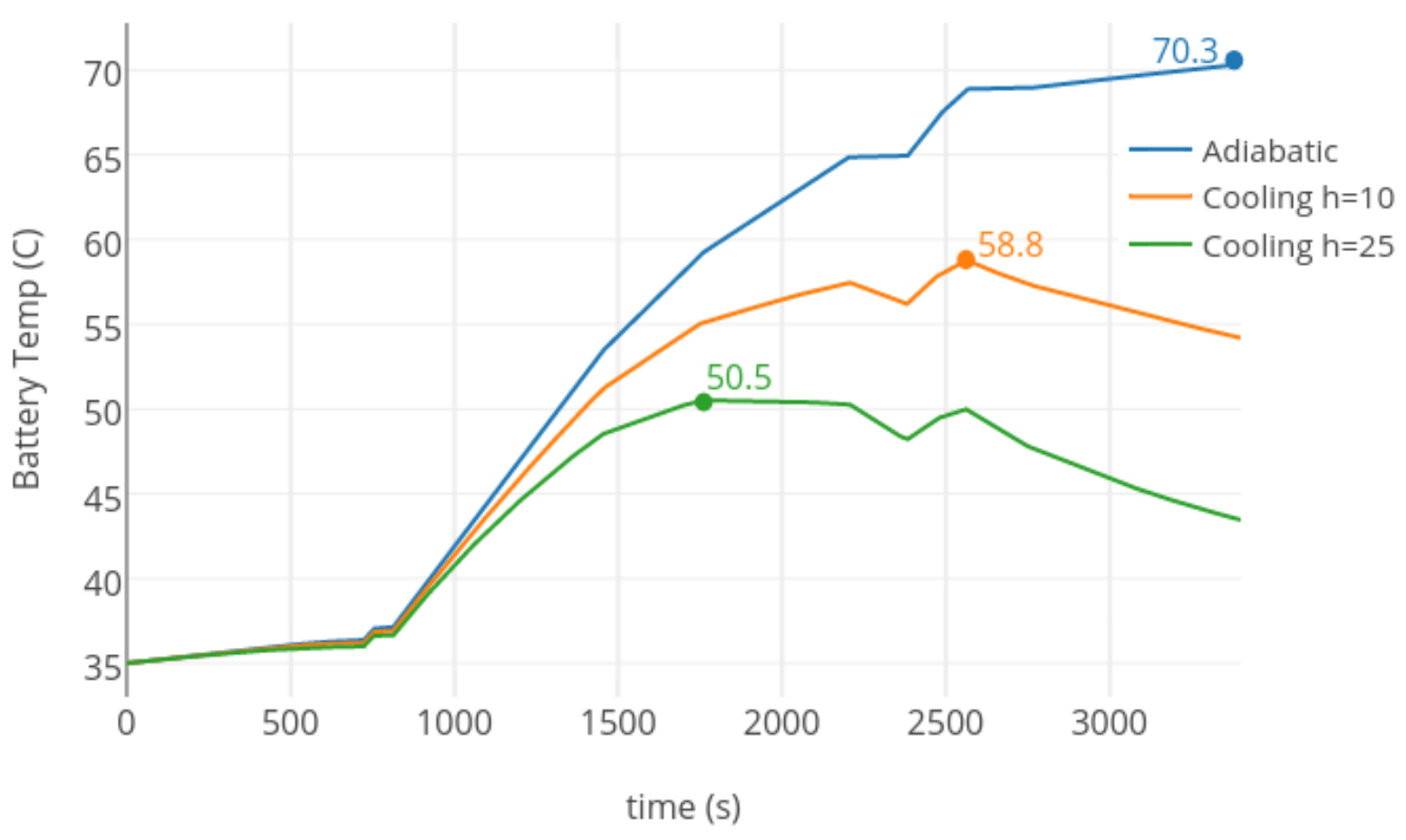

Figure 10. Temperature transients with various hypothetical cooling rates

The simplicity and flexibility of the lumped capacitance thermal script makes it a powerful tool for testing combinations of cooling schemes and flight profiles. Future work will incorporate dynamic polarization models, to better capture transients and state effects of the battery. This will better quantify non-linear thermal and voltage effects due to state of charge, temperature, and instantaneous current draw. ${ }^{9,10}$ Although these changes will improve fidelity of the model near the end of the battery's capacity, this initial model provides sufficient information to inform design and sizing in a timely manner. Battery performance testing is currently underway to better calibrate these higher fidelity models.

\section{High Lift Inverter Thermal Analysis}

The high lift motor is a key enabling technology for the X-57 Mod IV DEP concept. Twelve electric-driven propellers augment lift across the X-57's narrow wing during takeoff and landing. To meet the requirements for a short-duration, high power burst of extra propulsive power, the HLPs must be lightweight, power-dense and develop minimal parasitic drag during their inactive state. The X-57 HLPs are therefore conceptually similar to LEAPTech HEIST: ${ }^{11}$ a self-contained $14 \mathrm{~kW}$-class motor and controller in a wing-mounted pod. The greatest thermal load on the HLP assembly originates in the motor, with a cooler design beyond the scope of this paper. The other major heat load on the high lift nacelle is from the $10 \mathrm{~kW}$ motor controller, specifically the high power MOSFET transistor module. At the full power, a single HEIST controller must dissipate $220 \mathrm{~W}$ of thermal power without exceeding a case temperature of $120^{\circ} \mathrm{C}$. The controller cooler consists of a monolithic 6061 alloy heat sink that conforms to the outer mold line of the high lift nacelle.

In the interest of reducing parasitic drag during flight, the conformal sink cannot have any protruding fins, ducting, or features that otherwise disturb air flow. This naturally limits the amount of available surface area 

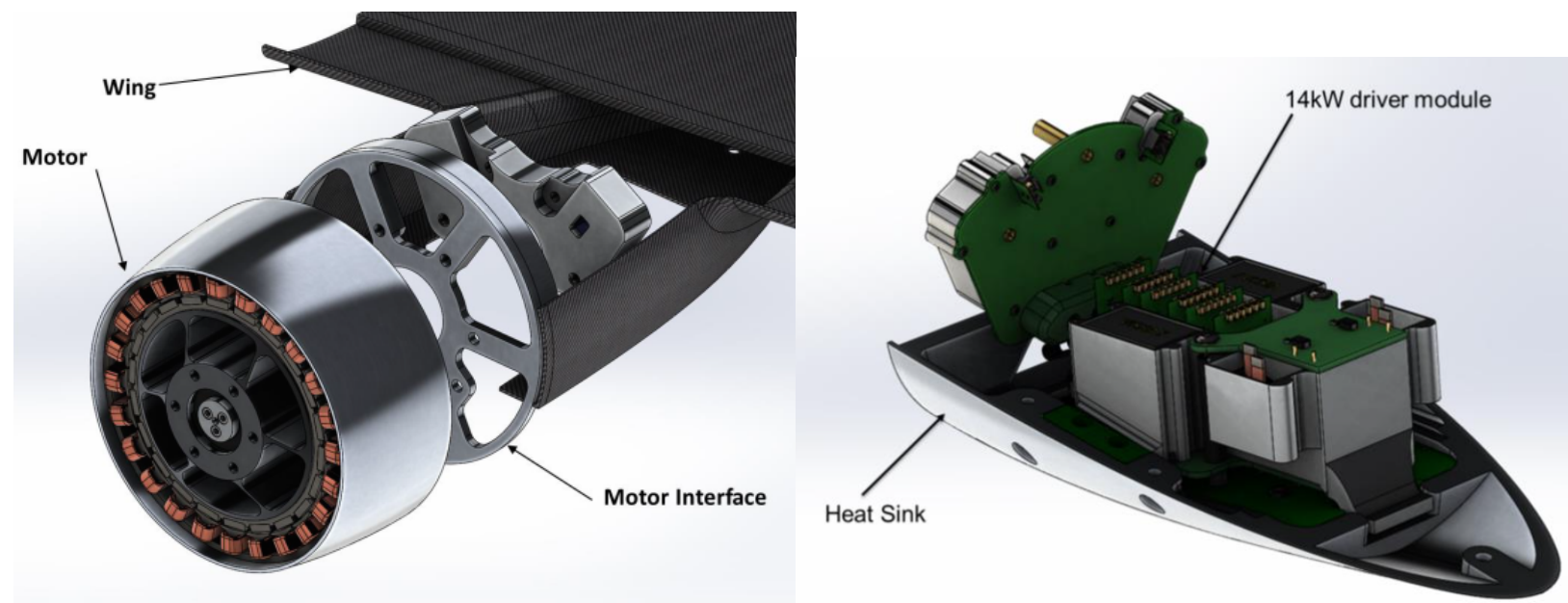

Figure 11. Depiction of HLP motor and heat sink

for rejecting heat to the free stream and it can be modeled with a simple convective heat transfer correlation for a primitive geometry. The conformal heat sink only represents a small section of the high lift nacelle surface area with a neutral aspect ratio, oriented approximately parallel to the direction of the free stream. For this reason it is treated like a 'pseudo flat plate', where heat transfer performance can be estimated with a simple convective heat transfer correlation for a constant heat flux surface. For an isothermal, constant heat flux, flat plate parallel flow $\left(R e_{L}<10^{5}\right)$, the general solution for plate surface temperature is,

$$
T_{\text {surface }}=\frac{Q_{\text {conv }}}{h_{\text {conv }} * A_{\text {conv }}}+T_{\text {ambient }}
$$

where $Q_{c o n v}$ is dissipated power, $h_{\text {conv }}$ and $A_{\text {conv }}$ are the convective heat transfer coefficient and surface area, and $T_{\text {ambient }}$ is the free stream temperature. The convective heat transfer coefficient, $h_{\text {conv }}$ is related to the Nusselt number, or ratio of convective to conductive heat transfer forces across the convective region,

$$
h_{\text {conv }}=\frac{N u_{L} * k}{L}
$$

where $\mathrm{L}$ is the sink characteristic length, and $\mathrm{k}$ is an average thermal conductivity of air between ambient and sink surface temperatures. The Nusselt number $\left(N u_{L}\right)$ for a flat plate geometry in laminar $\left(R e_{L}<10^{5}\right)$ flow is a function of the Reynolds and Prandtl numbers, ${ }^{12,13}$

$$
\begin{gathered}
N u_{L}=0.664 * \operatorname{Re}_{L}^{0.8} * \operatorname{Pr}^{0.33} \\
\operatorname{Re}_{L}\left(u_{0}, \nu\right)=\frac{u_{0} * L}{\nu}
\end{gathered}
$$

where $u_{0}$ is the free stream velocity parallel to the sink, and is the kinematic diffusivity of air at a given altitude and temperature.

The choice of sink characteristic length $L$, is critical when applying a generalized heat transfer correlation for a generic flat rectangular plate with a low aspect ratio. The HLP sink geometry is irregular, but can be mapped to the primitive correlation geometry by letting $L=$ convective area/perimeter. If the flat plate/sink parameters are chosen carefully, then the HLP heat sink isothermal temperature is a simple correlation of dissipated power, free stream velocity, and temperature. With these considerations in mind, an area of $0.0406 \mathrm{~m}^{2}$ and characteristic length of $.054 \mathrm{~m}$ was used. The spatial thermal gradient becomes negligible after the thermal load is applied for two minutes, as shown in a high-fidelity FEA COMSOL run depicted in Figure 12. 

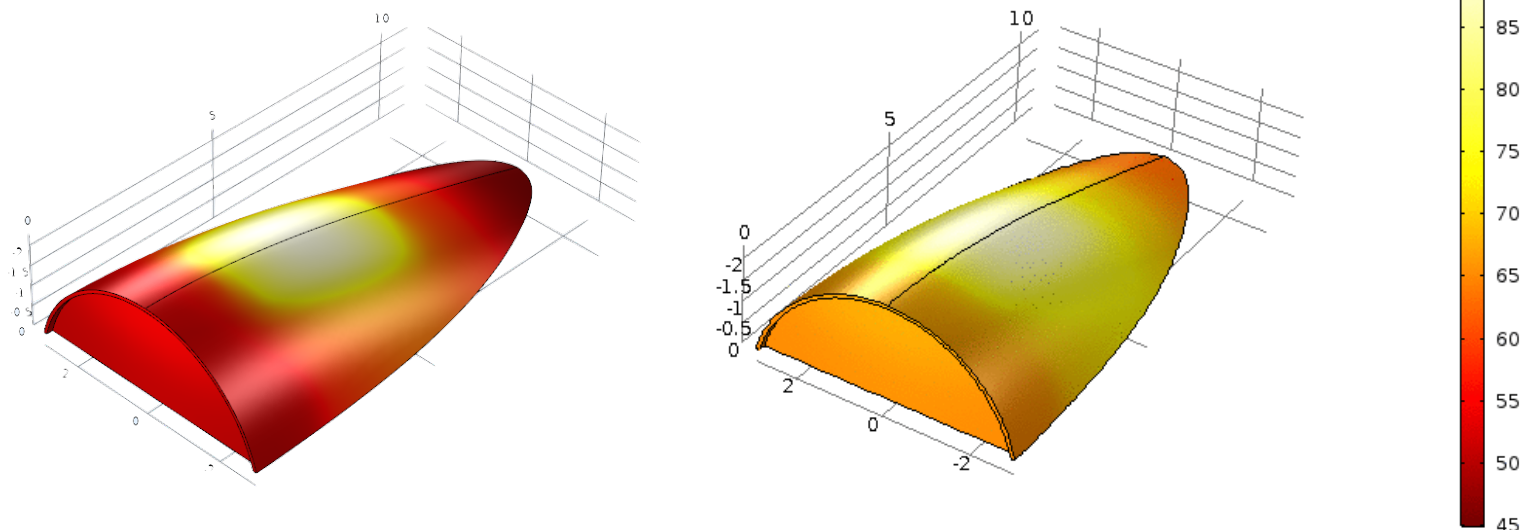

Figure 12. Transient COMSOL FEA results showing the lower convective area of HEIST nacelle, aft of the motor. (Left) After 1 minute (Right) After 2 minutes

\section{A. HEIST Results}

The accuracy of the HLP cooling model was evaluated using the GIMC-HEIST cooler at the NASA Glenn Research Facility's B5 facility. A laboratory-scale 8"x8" section thermal wind tunnel was configured to sweep dissipated power and free stream air velocity, and measure the temperature distribution across the sink with an assortment of embedded thermocouples and thermal cameras. A quick model validation was performed at the nominal max power setting for a simulated motor controller. A copper heater block produced $225 \mathrm{~W}$ of heater power, while the air speed inside the tunnel was varied between 4.5 and $21.6 \frac{\mathrm{m}}{\mathrm{s}}$ (the limit for that particular tunnel configuration). Computed steady-state heat transfer coefficients from the test largely agreed with the flat plate model assumptions:

\section{Model and Tested Convective Heat Transfer Coefficient vs}

\section{u0 at $\mathrm{Qh}=225 \mathrm{~W}$}

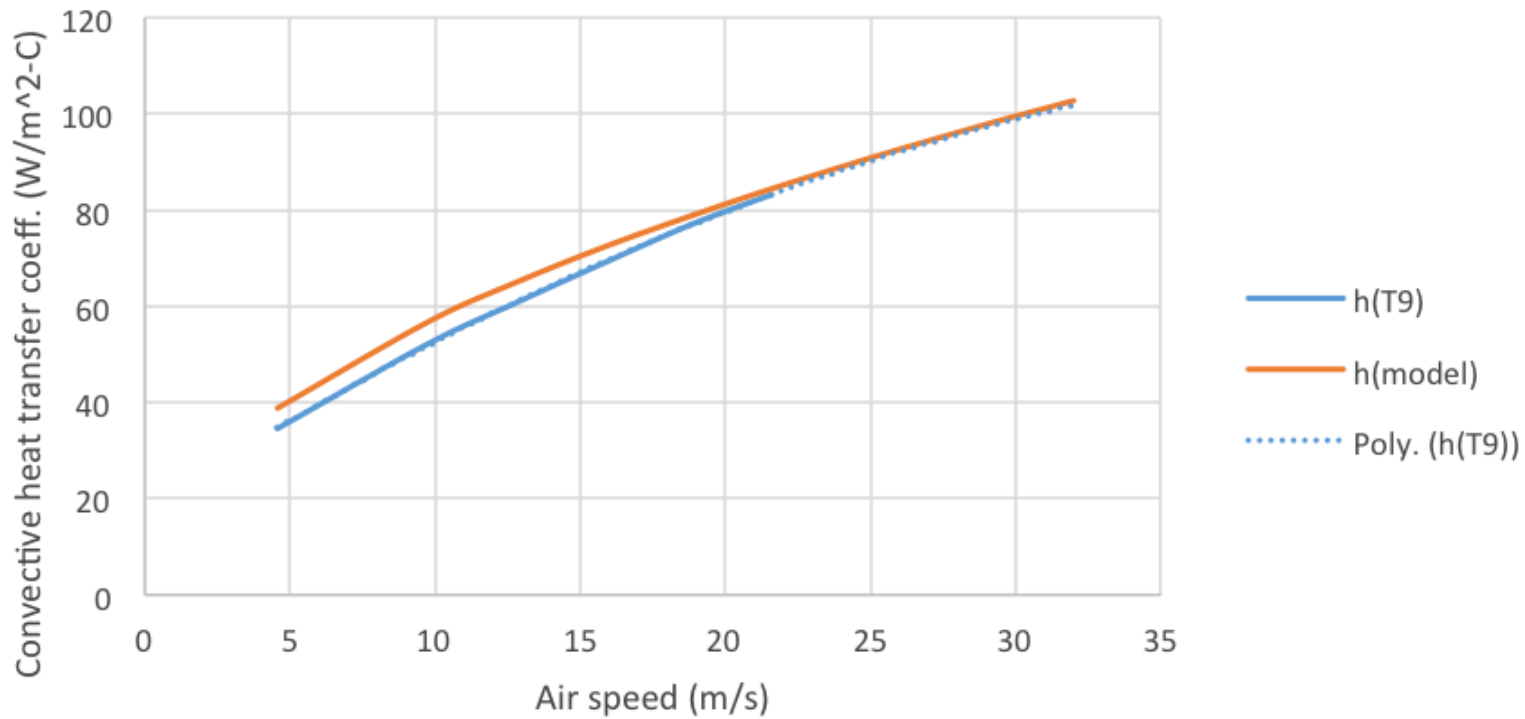

Figure 13. Plot of measured convective heat transfer coefficients at constant power, swept across a range of wind tunnel speeds. Plot overlaid with predicted values from the flat plate model.

The tested convection coefficient was based on the temperature at the center of the heater block, referenced to the facility temperature. At the highest tunnel speed, the flat plate model and heater blockreferenced heat transfer coefficient differed by no more than $1.5 \%$. This work assumes no additional cooling effects due to prop wash, based on the findings previous work done by Dubois and Christie. ${ }^{2}$ 


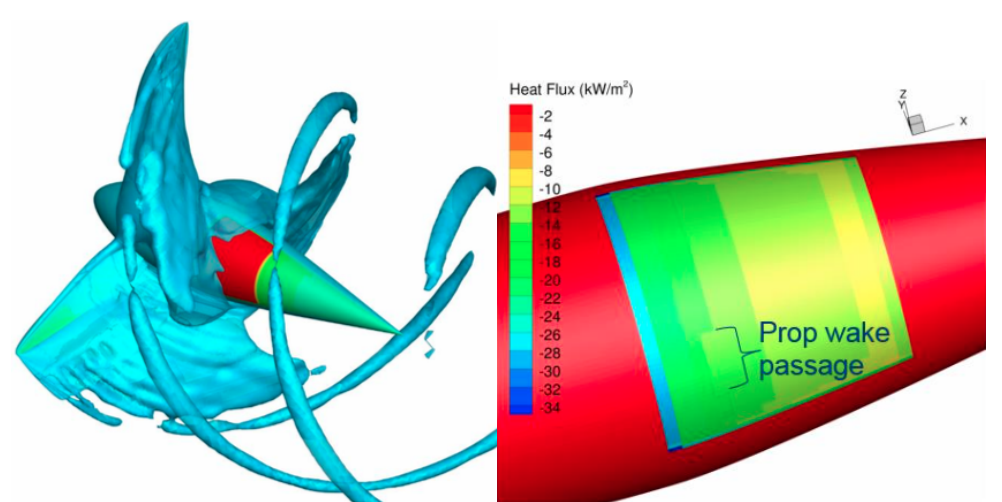

Figure 14. Prop wash cooling CFD results performed by Langley Research Center ${ }^{2}$

\section{Conclusions and Future Work}

Thermal profiles were estimated for the X-57 battery, wires, high lift motors, and wings using explicitly integrated low fidelity models based on experimental results. These models serve as conservative estimates to ensure sufficient thermal margin of existing designs for a specified mission profile. Through testing, it was shown that the thermal profile of multiple components could be distilled down into a lumped heat capacity and heat transfer coefficient. The high power wires could be tracked with a constant heat transfer coefficient, while the wing and high lift motor nacelles could be accurately modeled using a flat-plate approximation. These intentionally simple models provide the flexibility needed to quickly evaluate different mission scenarios and evolving designs. Additional research is underway to incorporate X-57 thermal constraints into a unified model based trajectory optimization, intended to maximize range or minimize travel time for a fixed range. ${ }^{8}$ This work could be further expanded by incorporating component sizing directly into the optimization.

\section{Acknowledgements}

The authors would like to thank the rest of the X-57 team, the NEAT facility, and the HEIST team for their collaboration. Additional thanks to the NASA Flight Demonstration and Capabilities Project for sponsoring this work.

\section{References}

\footnotetext{
${ }^{1}$ Borer, N. K., Patterson, M. D., Viken, J. K., Moore, M. D., Bevirt, J., Stoll, A. M., and Gibson, A. R., "Design and Performance of the NASA SCEPTOR Distributed Electric Propulsion Flight Demonstrator," 16th AIAA Aviation Technology, Integration, and Operations Conference, AIAA Aviation, American Institute of Aeronautics and Astronautics, jun 2016.

${ }^{2}$ Dubois, A., van der Geest, M., Bevirt, J., Christie, R., Borer, N. K., and Clarke, S. C., "Design of an Electric Propulsion System for SCEPTOR's Outboard Nacelle," 16th AIAA Aviation Technology, Integration, and Operations Conference, AIAA Aviation, American Institute of Aeronautics and Astronautics, jun 2016.

${ }^{3}$ Schnulo, S., Chin, J., and Smith, A., "Steady State Thermal Analyses of Wingtip Propulsor on SCEPTOR X-57," 2017.

${ }^{4}$ Turns, S., Thermal-fluid sciences: An integrated approach, Cambridge University Press, 2006.

5 "SciPy ODEint, https://docs.scipy.org/doc/scipy-0.18.1/reference/generated/scipy.integrate.odeint.html," 2016.

${ }^{6}$ Berton, J., An Experimental Investigation of Natural and Combined Convection from an Isothermal Horizontal Plate, Master's thesis, University of Illinois at Urbana-Champaign, 1986.

${ }^{7}$ Johnson, D., "Terrestrial Environment (Climatic) Criteria Guidelines for use in Aerospace Vehicle Development," 2008.

${ }^{8}$ Falck, R., Chin, J., Schnulo, S., Burt, J., and Gray, J., "Trajectory Optimization of Electric Aircraft Subject to Subsystem Thermal Constraints," 2016.

${ }^{9}$ Huria, T., Ceraolo, M., Gazzarri, J., and Jackey, R., "High Fidelity Electrical Model with Thermal Dependence for Characterization and Simulation of High Power Lithium Battery Cells," Electric Vehicle Conference (IEVC), pp 1-8, IEEE International, March 2012.

${ }^{10} \mathrm{He}, \mathrm{H} .$, Rui, X., and Jinxin, F., "Evaluation of lithium-ion battery equivalent circuit models for state of charge estimation by an experimental approach," Electric Vehicle Conference (IEVC), 4.4 582-598, Energies, March 2011.

${ }^{11}$ Papathakis, Kurt, K. K. L. Y. C. S. and Ginn, S., "Design and Development of a 200-kW Turbo-electric Distributed Propulsion Testbed," June 2016.

${ }^{12}$ Churchill, S. and Chu, H., "Correlating Equations for Laminar and Turbulent Free Convection from a Horizontal Cylinder," 1975.

${ }^{13}$ Clausing, A., "Simple Functional Representations for the Thermophysical Properties of Gases at Standard Pressure," 1982.
} 